\title{
The effect of vasectomy on the testes of inbred Lewis rats
}

\author{
W. B. Neaves \\ Department of Cell Biology, University of Texas, Southwestern Medical School and \\ Graduate School of Biomedical Sciences, 5323 Harry Hines Boulevard, Dallas, Texas 75235, \\ U.S.A.
}

\begin{abstract}
Summary. By 3 months after surgery, testicular weights were $12-14 \%$ below control values in a large series of vasectomized rats of the inbred Lewis strain. Testicular sperm concentrations in the vasectomized rats were $25-29 \%$ below those in the sham-operated animals. Although modest in magnitude, these differences were highly significant $(P<0.001)$. Histometric analysis of testes from a smaller series of vasectomized Lewis rats revealed various proportions of abnormal seminiferous tubules. The degenerative changes included reduction in tubule diameter, fusion of spermatids, and depletion of advanced germinal elements. In the most severely affected tubules, leakiness of the blood-testis barrier was indicated by penetration of lanthanum through Sertoli-cell tight junctions.
\end{abstract}

\section{Introduction}

Whether or not vasectomy adversely influences the rat testis has been a question of considerable controversy (see review by Neaves, 1975a). In contrast to the disagreement resulting from earlier reports, recent experiments support the view that testicular atrophy does not occur in rats that have been surgically vasectomized for less than 1 year (Heller \& Rothchild, 1974; McGlynn \& Erpino, 1974; Neaves, 1974; Hernández-Jáuregui \& Olivera, 1975; Howards, Jessee \& Johnson, 1975; Mock, Kamel, Wright \& Frankel, 1975; Neaves, 1975b; Voglmayr, 1975; Kuwahara, 1976; Lohiya, Dixit \& Arya, 1976; Reinke \& Stohs, 1977). These studies were confined to outbred rats, primarily to those of the Sprague-Dawley strain. It has been shown that an immune response to sperm antigens occurs after vasectomy in some rat strains but not in others (Bigazzi, Kosuda \& Harnick, 1977). Bigazzi et al. (1977) were unable to detect sperm autoantibodies in vasectomized rats of the Sprague-Dawley strain but did find such antibodies in $80 \%$ of inbred rats belonging to the Lewis strain.

An immune response to sperm antigens has been implicated in the testicular damage occurring after vasectomy in some species, e.g. guinea-pig (Alexander, 1973) and rabbit (Bigazzi, Kosuda, Hsu \& Andres, 1976). In guinea-pigs, the coexistence of both serum-and cell-mediated immunity to sperm antigens has been shown to facilitate development of testicular abnormality (Voisin \& Toullet, 1969) and vasectomized guinea-pigs manifest both types of sperm-specific immunity (Alexander, 1973). Brannen \& Coffey (1974) and Brannen, Kwart \& Coffey (1974) found that Lewis-strain rats vasectomized with ligation of the ductus deferens developed serum-mediated immunity to sperm antigens, whereas those vasectomized without ligation developed cell-mediated immunity. These findings suggested that a favourable strategy for eliciting impairment of the testes of Lewis rats would entail bilateral vasectomy with one ductus deferens ligated and the other unligated. We have therefore examined this strategy in a large series of Lewis rats.

\section{Materials and Methods}

Inbred rats of the Lewis strain were obtained from Microbiological Associates (Walkersville, Maryland) at 2 months of age. After acclimatization for 2 weeks in our animal colony, equal numbers of rats were randomly assigned to experimental groups designated as sham-operated or vasectomized. 
Surgery was performed with strict aseptic precautions on rats anaesthetized with an aqueous solution of chloral hydrate $(30 \mathrm{mg} / \mathrm{ml} / 100 \mathrm{~g}$ body weight) administered by intraperitoneal injection. Each ductus deferens was exposed near its distal end by a mid-line incision in the lower abdominal wall, and a $2 \mathrm{~cm}$ segment of each ductus was carefully dissected free of the deferent artery without damaging this source of collateral circulation to the testis. In sham-operated rats, the abdominal musculature was sutured with $5-0$ chromic gut, and the skin margins were approximated with $9 \mathrm{~mm}$ clips after dusting the wound with nitrofurazone powder. In vasectomized rats, the freed segment of the left ductus deferens was isolated by 4-0 silk ligatures and $1 \mathrm{~cm}$ of the intervening ductus was excised. On the right side, $1 \mathrm{~cm}$ of the freed segment of ductus deferens was excised without ligation. The operation was then completed as described for sham-operated rats.

Rats were housed in the animal colony during the experiment and were examined each day to ensure that testes remained in the scrotum and that good health was maintained. At 3 months after surgery, each rat was weighed to the nearest $1.0 \mathrm{~g}$ and decapitated. Testes, epididymides, and sperm cysts were weighed to the nearest $0.005 \mathrm{~g}$. Each testis was decapsulated, forced through a 100 -mesh stainless-steel sieve, and suspended in $5 \mathrm{ml}$ saline (0.154 M-NaCl). A 1:10 dilution of this suspension was examined in a phase-contrast haemocytometer, and all mature spermatids and spermatozoa were counted in four $0.1 \mathrm{~mm}^{3}$ compartments. The total number of spermatozoa counted in each dilution was between 100 and 400 . The accuracy of the count was better than $10 \%$ as determined by counting duplicate dilutions of the same suspension. Haemocytometer counts were converted to $1 \times 10^{6}$ spermatozoa/g testis.

Correlation coefficients were calculated for pairs of selected variables in each group. The results of statistical tests of difference were considered significant if $P<0.05$.

An additional series of similarly vasectomized and sham-operated rats was killed 3 months after surgery for histometric analysis of the testis and for ultrastructural assessment of the permeability of the blood-testis barrier. Each testis was divided by equatorial section, and a $2 \mathrm{~mm}$-thick slice from the cut surface of the caudal half was immersed in a $1 \%$ solution of lanthanum silicate in cacodylatebuffered glutaraldehyde and processed for electron microscopy as described previously (Neaves, 1973). The cranial half and remainder of the caudal half of the testis were immersed in Bouin's fixative, embedded in paraffin wax, sectioned at $8 \mu \mathrm{m}$, stained with haematoxylin and eosin, and subjected to histometric analysis. Seminiferous tubules were categorized as normal (typical constellations of spermatogenic cells represented in the seminiferous epithelium) or abnormal (evident depletion of germinal elements), and the diameters of 40 tubules in each category were measured with an ocular micrometer at $\times 100$. Estimation of the proportion of the mass of seminiferous tubules represented by abnormal tubules was made by the sampling technique of Chalkley (1943). Using a ten-point grid in a $\times 10$ ocular, testis sections were examined with $a \times 10$ objective lens at 40 sites randomly selected by predetermined movements of the microscope stage. By comparing the number of points over abnormal tubules with those over normal tubules, the percentage of abnormal tubules in each testis was determined. Duplicate determinations performed on the same specimens showed that the precision of this method was $\pm 5 \cdot 3 \%$.

\section{Results}

Small but significant reduction in testicular weight occurred in the vasectomized rats, the right and left testes being 12 and $14 \%$ respectively below control values (Table 1 ). The testicular sperm concentrations were also reduced, by 25 and $29 \%$ for the right and left testes compared to their respective controls (Table 1). In spite of high coefficients of variation for testicular sperm concentration in vasectomized rats ( 65 and $68 \%$ for right and left testes, respectively), the reduction in this parameter was significant. Severe reduction in testicular sperm concentration was judged to occur when values fell below $10 \%$ of normal (i.e. below $4.0 \times 10^{6} / \mathrm{g}$ ). Such severe reduction was encountered four times as frequently in vasectomized rats compared to sham-operated controls (17 rats versus 4 rats, respectively) and was associated with a $50-70 \%$ reduction in testis weight. 
Table 1. Comparison of body, testis, epididymis and sperm cyst weights and of testicular spermatozoa concentrations in sham-operated and vasectomized Lewis rats 3 months after surgery

\begin{tabular}{lccc}
\hline & $\begin{array}{c}\text { Sham-operated } \\
(\mathrm{N}=79)\end{array}$ & $\begin{array}{c}\text { Vasectomized } \\
(\mathrm{N}=79)\end{array}$ & Significance* \\
\hline Weight of: & & & \\
$\quad$ Body $(\mathrm{g})$ & $400 \pm 5 \dagger$ & $403 \pm 5$ & $P>0.6$ \\
Left testis $(\mathrm{g})$ & $1.38 \pm 0.03$ & $1.18 \pm 0.05$ & $P<0.001$ \\
Right testis $(\mathrm{g})$ & $1.39 \pm 0.04$ & $1.22 \pm 0.04$ & $P<0.005$ \\
Left epididymis $(\mathrm{g})$ & $0.54 \pm 0.01$ & $0.52 \pm 0.01$ & $P>0.2$ \\
Right epididymis $(\mathrm{g})$ & $0.55 \pm 0.01$ & $0.53 \pm 0.01$ & $P>0.1$ \\
Left sperm cyst $(\mathrm{g})$ & - & $0.26 \pm 0.02$ & - \\
Right sperm cyst $(\mathrm{g})$ & - & $0.27 \pm 0.02$ & - \\
Sperm concentration in: & & & \\
Left testis $\left(\times 10^{6} / \mathrm{g}\right)$ & $38.5 \pm 1.6$ & $27.3 \pm 2.1$ & $P<0.001$ \\
Right testis $\left(\times 10^{6} / \mathrm{g}\right)$ & $37.2 \pm 1.5$ & $27.8 \pm 2.0$ & $P<0.001$ \\
\hline
\end{tabular}

* Probability that sample means are not different by Student's $t$ test.

Values are mean \pm s.e.m.

The sham-operated and vasectomized rats showed a positive correlation between testicular weight and sperm concentration (Table 2). Correlation coefficients were similar from side to side in each group, but those for each side were significantly higher in the vasectomized animals (Table 2). The higher correlation coefficients between testicular weight and sperm concentration in vasectomized rats reflected the increased incidence of small, functionally impaired testes in this group.

Table 2. Sample correlation coefficients $(r)$ between weight of and sperm concentration in testes of sham-operated and vasectomized Lewis rats 3 months after surgery

\begin{tabular}{|c|c|c|c|}
\hline & $\begin{array}{l}\text { Sham-operated } \\
(\mathrm{N}=79)\end{array}$ & $\begin{array}{l}\text { Vasectomized } \\
\quad(\mathrm{N}=79)\end{array}$ & Significance \\
\hline Right testis & 0.62 & 0.81 & $P<0.02$ \\
\hline Left testis & 0.68 & 0.85 & $P<0.01$ \\
\hline Significance & $P>0.5$ & $P>0.4$ & \\
\hline
\end{tabular}

\footnotetext{
* Probability that the samples are drawn from populations with identical correlation coefficients.
}

There were no differences in response between right and left sides for testicular weight and sperm concentration (Table 1), and sperm cysts developed equally on the two sides of the vasectomized rats regardless of whether the ductus deferens was ligated or unligated (Table 1). Based on earlier calculations for Sprague-Dawley rats (Neaves, 1975a), the mean weight of these cysts was proportional to the average mass of spermatozoa estimated to have been produced by each testis after vasectomy.

The findings for the 5 vasectomized and 5 sham-operated rats studied microscopically are summarized in Table 3. One sham-operated rat had one abnormally small testis, while both testes were below normal weight in 3 of the vasectomized rats. The mean \pm s.e.m. weights for the left and right testes of the 5 vasectomized rats $(1.22 \pm 0.16 \mathrm{~g}$ and $1 \cdot 14 \pm 0.14 \mathrm{~g}$, respectively) and of the 5 shamoperated rats $(1.57 \pm 0.08 \mathrm{~g}$ and $1.44 \pm 0.14 \mathrm{~g})$ were similar to those of the larger series in Table 1 , and confirmed that there was a reduction in testicular weight attributable to vasectomy.

Histometric analysis of the abnormally small control testis revealed that $42 \%$ of its tubular mass was represented by narrow seminiferous tubules lacking most germinal elements. These degenerate 
tubules were not dispersed among normal tubules but were confined to one sagittal half of the testis, suggestive of a localized traumatic injury. The remainder of the tubules in this testis as well as all tubules observed in the other sham-operated rats were normal in diameter (Table 3) and in structure (Pl. 1, Figs 1 and 2). The diameters of normal seminiferous tubules in sham-operated rats and in vasectomized rats with fewer than $15 \%$ abnormal tubules were similar (Table 3 ). In vasectomized rats with more than $30 \%$ abnormal tubules, the diameter of apparently normal tubules was reduced by approximately $20 \%$ (Table 3 ) and therefore the most severely affected testes exhibited a reduction in diameter of 'normal' tubules as well as a high incidence of abnormal (germ-cell depleted) tubules.

Table 3. Testicular weight, diameters (mean \pm s.e.m., 40 tubules/testis: see text) of normal and abnormal tubules and percentage of seminiferous tubules obviously abnormal in 5 vasectomized and 5 sham-operated Lewis rats 3 months after surgery

\begin{tabular}{|c|c|c|c|c|c|}
\hline Animal & 1 testis & $\begin{array}{l}\text { Testicular } \\
\text { wt (g) }\end{array}$ & $\begin{array}{l}\text { Diameter of } \\
\text { normal } \\
\text { tubules }(\mu \mathrm{m})\end{array}$ & $\begin{array}{l}\% \text { Abnormal } \\
\text { tubules }\end{array}$ & $\begin{array}{l}\text { Diameter of } \\
\text { abnormal } \\
\text { tubules }(\mu \mathrm{m})\end{array}$ \\
\hline \multicolumn{6}{|c|}{ Vasectomized rats } \\
\hline 1 & $\begin{array}{l}\text { Right } \\
\text { Left }\end{array}$ & $\begin{array}{l}1 \cdot 13 \\
1.04\end{array}$ & $\begin{array}{l}215 \pm 3 \\
206 \pm 4\end{array}$ & $\begin{array}{l}32 \\
61\end{array}$ & $\begin{array}{l}180 \pm 3 \\
186 \pm 2\end{array}$ \\
\hline \multirow[t]{2}{*}{2} & Right & 1.57 & $270 \pm 4$ & $\mathbf{0}$ & - \\
\hline & Left & 1.58 & $254 \pm 4$ & 0 & - \\
\hline \multirow[t]{2}{*}{3} & Right & 1.65 & $256 \pm 3$ & 0 & - \\
\hline & Left & 1.36 & $255 \pm 4$ & 11 & $159 \pm 4$ \\
\hline \multirow[t]{2}{*}{4} & Right & 0.88 & $255 \pm 3$ & 14 & $155 \pm 3$ \\
\hline & Left & 0.87 & $256 \pm 3$ & 11 & $167 \pm 3$ \\
\hline \multirow[t]{2}{*}{5} & Right & 0.89 & $216 \pm 4$ & 65 & $178 \pm 2$ \\
\hline & Left & 0.84 & $202 \pm 3$ & 79 & $177 \pm 3$ \\
\hline \multicolumn{6}{|c|}{ Sham-operated rats } \\
\hline \multirow[t]{2}{*}{1} & Right & $1 \cdot 32$ & $252 \pm 3$ & 0 & - \\
\hline & Left & 0.89 & $266 \pm 3$ & 42 & $151 \pm 1$ \\
\hline \multirow[t]{2}{*}{2} & Right & 1.52 & $257 \pm 3$ & $\mathbf{0}$ & - \\
\hline & Left & 1.51 & $261 \pm 3$ & 0 & - \\
\hline \multirow[t]{2}{*}{3} & Right & $1 \cdot 54$ & $260 \pm 3$ & $\mathbf{0}$ & - \\
\hline & Left & 1.51 & $250 \pm 3$ & 0 & - \\
\hline \multirow[t]{2}{*}{4} & Right & 1.78 & $255 \pm 3$ & 0 & - \\
\hline & Left & 1.73 & $254 \pm 3$ & $\mathbf{0}$ & - \\
\hline \multirow[t]{2}{*}{5} & Right & 1.69 & $269 \pm 3$ & $\mathbf{0}$ & - \\
\hline & Left & 1.57 & $255 \pm 3$ & 0 & - \\
\hline
\end{tabular}

The abnormal tubules in the affected vasectomized rats occurred throughout the testis, often scattered among apparently normal tubules (PI. 1, Fig. 3), and lacked the usual constellations of germinal elements. Although shedding of spermatocytes was occasionally seen (Pl. 1, Fig. 4), progressive fusion of spermatids was the most characteristic feature of degenerating seminiferous epithelia (Pl. 1, Fig. 5), and it produced distinctive spherical masses of cytoplasm containing a central concentration of acrosomal material and a peripheral ring of nuclei (PI. 1, Fig. 6). Release of fused spermatids into the tubule lumen ultimately left the seminiferous epithelium with only Sertoli cells and scattered spermatogonia. No evidence of lymphoid cell involvement in the degenerative process was detected.

The status of the blood-testis barrier was assessed by electron microscopic observation of lanthanum distribution within extracellular spaces of the seminiferous epithelium. Only normal tubules were represented in testicular samples from sham-operated rats that were fixed in the presence of lanthanum. In all these, lanthanum was confined to the basal compartment of the seminiferous epithelium by tight junctions between Sertoli cells. The diffusion of lanthanum in normal tubules of 

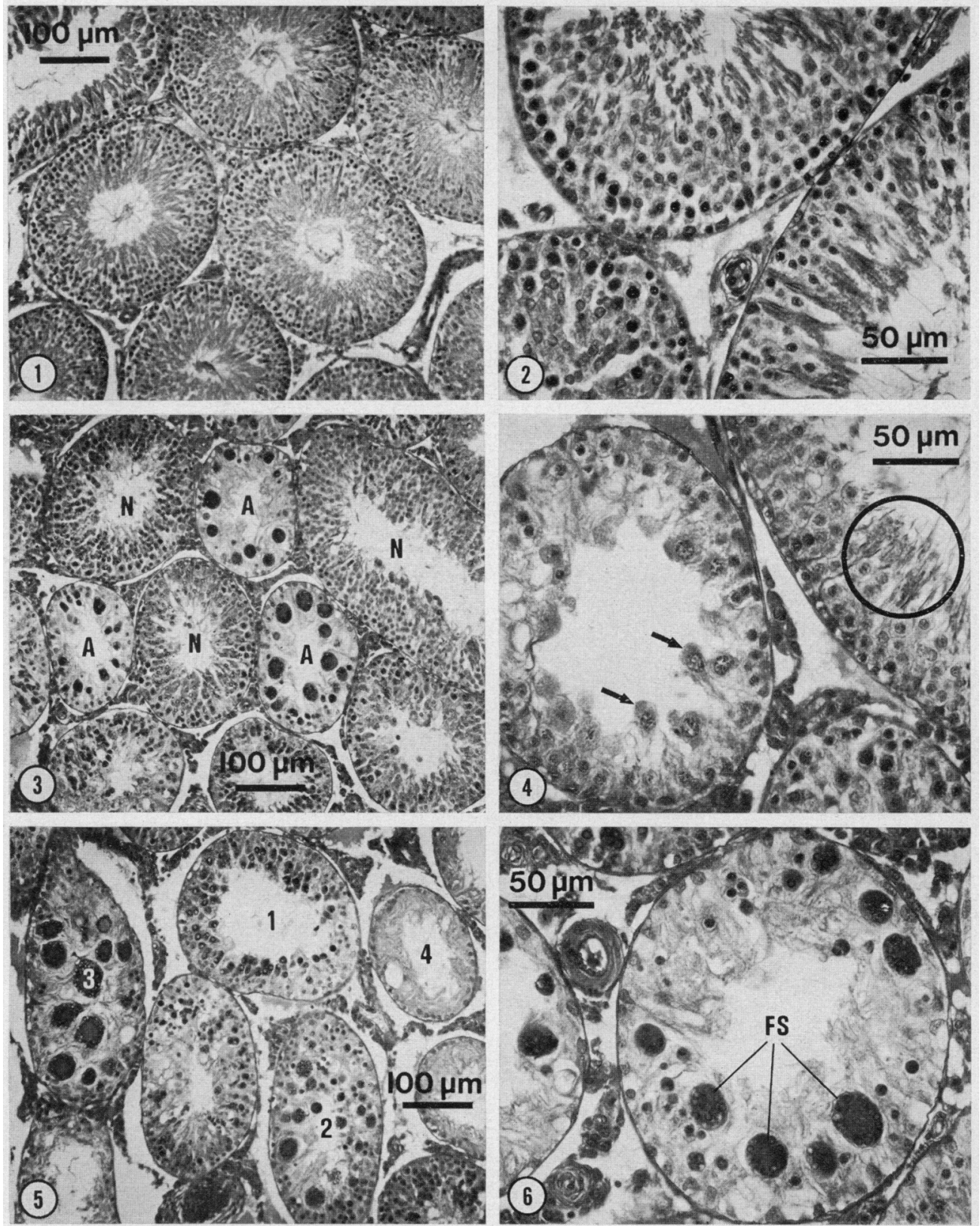

Lewis rat testes collected 3 months after vasectomy or sham-operation.

Fig. 1. Normal seminiferous tubules from sham-operated rat.

Fig. 2. Higher magnification of normal seminiferous tubules from shan-operated rat.

Fig. 3. Seminiferous tubules from a vasectomized rat, showing normal (N) and abnormal (A) tubules.

Fig. 4. Seminiferous epithelia from a vasectomized rat. Loss of germinal elements is illustrated by apparent shedding of spermatocytes (arrows) into the lumen of an abnormal tubule. The epithelium of the adjacent tubule shows a normal population of germinal elements, including numerous late spermatids (circle).

Fig. 5. Seminiferous tubules from a vasectomized rat. The hierarchy of abnormality is indicated by tubules with various degrees of spermatid fusion $(1-3)$ and by a tubule with virtually complete loss of germinal elements (4).

Fig. 6. Seminiferous epithelium from vasectomized rat, showing fused spermatids (FS). 

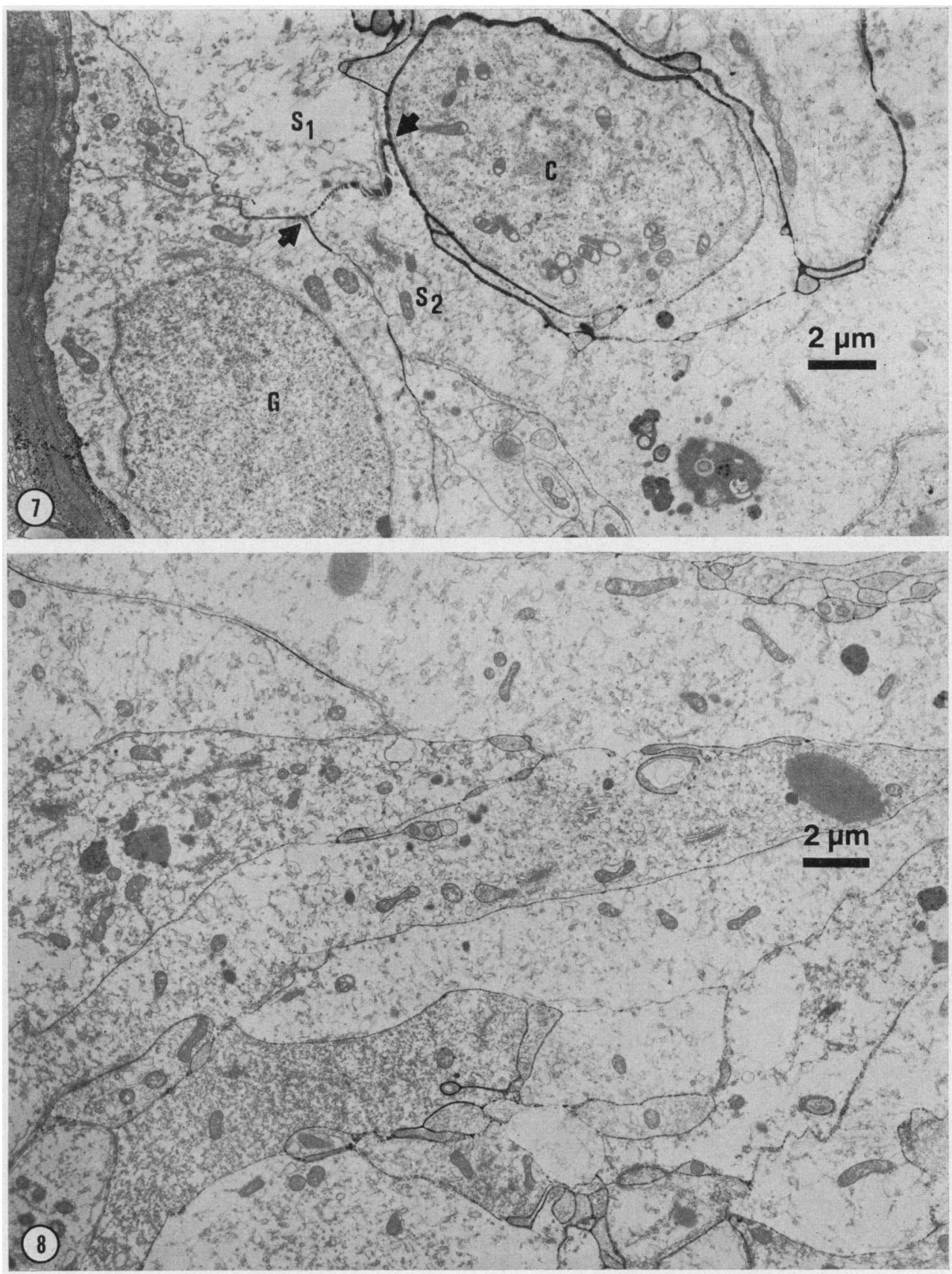

Lewis rat testes collected 3 months after vasectomy and fixed in the presence of lanthanum for electron microscopy (see text).

Fig. 7. Basal zone of seminiferous epithelium from an abnormal tubule. In addition to its usual presence around a spermatogonium $(G)$, the lanthanum has penetrated the junctional complex (between pairs of arrows) of adjacent Sertoli cells $\left(S_{1}\right.$ and $\left.S_{2}\right)$ and fills the extracellular space around a spermatocyte $(C)$.

Fig. 8. Apical zone of seminiferous epithelium from an abnormal tubule depleted of germinal elements. Apical processes of Sertoli cells are separated by narrow extracellular spaces containing lanthanum deposits. 
vasectomized rats was similarly checked by Sertoli-cell tight junctions. Leaky tight junctions appeared only in tubules in which there was severe depletion of germinal elements. Leaky junctions were occasionally observed in tubules with a few remaining advanced germinal elements, such as spermatocytes (Pl. 2, Fig. 7), but extensive lanthanum penetration into the adluminal compartment was usually seen in tubules lacking all germinal elements except spermatogonia (Pl. 2, Fig. 8).

\section{Discussion}

Bigazzi et al. (1977) noted the lack of uniformity in results of studies on the effects of vasectomy in rats and suggested that it be attributed to the difficulty of comparing results from investigations performed with different strains of rats. If the investigations cited by Bigazzi et al. (1977) are categorized according to the strain of rat used, five studies were performed with Sprague-Dawley rats; in four there was no change after vasectomy (Flickinger, 1972; Heller \& Rothchild, 1974; Neaves, 1974; Mock et al., 1975), but there was a decline in testicular weight in the other (Thakur, Sheth \& Rao, 1972). Of three studies using Wistar rats, changes were reported after vasectomy in two (Sadi, Chiorboli \& Saad, 1967; Sackler, Weltman, Pandhi \& Schwartz, 1973), and no alterations were found in the other (McGlynn \& Erpino, 1974). It therefore appears that disparate results are not eliminated by confining the comparison to specific strains of rats.

Other investigators have presented evidence suggesting that non-specific side effects resulting from differences in surgical technique and post-operative care are responsible for much of the earlier controversy surrounding the effects of vasectomy in outbred rats (Heller \& Rothchild, 1974; Neaves, 1974). For example, the testes of a vasectomized rat may undergo degenerative changes resulting from surgically induced thermoregulatory defects or vascular impairments that are unrelated to discontinuity of the ductus deferens (Neaves, 1975a). In the present study, prevention of post-operative complications such as infection and cryptorchidism and protection of the collateral blood supply to the testis have minimized the possibility that the observed changes in testis weight and sperm concentration were side effects of surgery rather than specific consequences of vasectomy.

Hypothetical mechanisms of testicular damage specifically related to vasectomy include elevation of intratubular pressure, interference with hormonal requirements of spermatogenesis, and development of aggressive autoimmunity against sperm antigens. In species such as the hamster (Johnson \& Howards, 1975) and the guinea-pig (Johnson \& Howards, 1976), direct measurements of intratubular hydrostatic pressure have shown that vasectomy does not result in elevated pressure within the testis. Indirect evidence suggests that the same may be true in Sprague-Dawley rats (Neaves, 1973). The apparent normality of testosterone levels after vasectomy in rats (Mock et al., 1975; Neaves, 1975b; Voglmayr, 1975; Kuwahara, 1976) has not encouraged pursuit of hormonal mechanisms of spermatogenic impairment, and more study has been devoted to sperm-specific autoimmunity because of its evident involvement in post-vasectomy hypospermatogenesis in guinea-pigs (Alexander, 1973) and rabbits (Bigazzi et al., 1976).

Microscopic examination of the testes from vasectomized Lewis rats yielded a spectrum of findings ranging from completely normal seminiferous tubules in some testes to frank degeneration of up to $79 \%$ of the tubule mass in others. Degenerative changes were characterized by a patchy distribution of reduction in tubule diameter, fusion of spermatids, and ultimate loss of advanced germinal elements from the seminiferous epithelium. The average $25-29 \%$ reduction in testicular sperm concentration measured in vasectomized Lewis rats cannot therefore be attributed to a uniform suppression of spermatogenesis throughout the testis.

Distribution of lanthanum tracer in the seminiferous epithelium indicated leakiness of the bloodtestis barrier in the most degenerate seminiferous tubules of the vasectomized rats, but the change to the barrier could precede or follow the severe epithelial degeneration. Substantial abnormality (i.e. spermatid fusion) can occur in tubules in which there is no lanthanum penetration of Sertoli-cell tight junctions. The intact blood-testis barrier should have precluded direct access of sperm-specific antibodies to advanced germinal elements higher in the epithelium in such tubules but it is possible that 
antibodies have entered the lumen elsewhere. Although the present data do not clarify the role of the blood-testis barrier in the development of vasectomy-induced lesions, they do indicate the involvement of barrier leakiness in the disorder in Lewis rats. This finding contrasts with the uncompromised integrity of the blood-testis barrier in vasectomized Sprague-Dawley rats (Neaves, 1973).

The cause of degenerative changes in the seminiferous tubules of most vasectomized Lewis rats is unclear, but the following points have emerged from the present study. (1) The basis of the change must reside in a strain-specific susceptibility, because other rat strains, such as Sprague-Dawley, do not exhibit testicular abnormality after vasectomy (Neaves, 1974). (2) If autoimmunity to sperm antigens is a factor in vasectomy-induced testicular abnormality among Lewis rats, humoral rather than cell-mediated immunity must be active at the level of the testis, because no evidence of lymphoid cell infiltration of the interstitium or invasion of the seminiferous tubules could be detected in this study. (3) Any mechanism invoked to explain degenerative changes in the testes of vasectomized Lewis rats must account for the variable expression of the disorder and, in most cases, the simultaneous and contiguous existence of normal and degenerate tubules. An interaction of immunological and physical factors could account for the pattern of change observed in this study.

This research was supported by grants from the Ford Foundation and the Population Council. I thank Mr M. McClung for skilled technical assistance and also $\mathrm{Mr} \mathrm{N}$. Lewandos and Ms Laura Burgess.

\section{References}

Alexander, N.J. (1973) Autoimmune hypospermatogenesis in vasectomized guinea pigs. Contraception 8 , 147-164.

Bigazzi, P.E., Kosuda, L., Hsu, K.C. \& Anders, G.A. (1976) Immune complex orchitis in vasectomized rabbits. $J$. exp. Med. 143, 382-404.

Bigazzi, P.E., Kosuda, L. \& HaRnick, L. (1977) Sperm autoantibodies in vasectomized rats of different inbred strains. Science, N.Y. 197, 1282-1283.

BranNen, G.E. \& CoFFeY, D.S. (1974) Immunologic implications of vasectomy. II. Serum-mediated immunity. Fert. Steril. 25, 515-520.

Brannen, G.E., Kwart, A.M. \& Coffey, D.S. (1974) Immunologic implications of vasectomy. II. Cellmediated immunity. Fert. Steril. 25, 508-514.

Chalkley, H.W. (1943) Method for the quantitative morphological analysis of tissues. J. natn. Cancer Inst. 4, 47-53.

Flickinger, C.J. (1972) Ultrastructure of the rat testis after vasectomy. Anat. Rec. 174, 477-493.

Heller, G.V. \& Rothchild, I. (1974) The influence of the surgical technique used for vasectomy on testis function in rats. $J$. Reprod. Fert. 39, 81-89.

Hernández-JÁuregui, P. \& Olivera, J. (1975) A study of the morphology of the Leydig cells of the rat after unilateral vasectomy. J. Reprod. Fert. 45, 405407.

Howards, S.S., Jessee, S. \& Johnson, A. (1975) Micropuncture and microanalytic studies of the effect of vasectomy on the rat testis and epididymis. Fert. Steril. 26, 20-28.

JoHNSON, A.L. \& HowARDS, S.S. (1975) Intratubular hydrostatic pressure in testis and epididymis before and after vasectomy. Am. J. Physiol. 228, 556564.

Johnson, A.L. \& Howards, S.S. (1976) Intratubular hydrostatic pressure in testis and epididymis before and after long-term vasectomy in the guinea pig. Biol. Reprod. 14, 371-376.

KuWAHARA, M. (1976) The effects of ligation of vas deferens, corpus epididymidis, and vasa efferentia on the testicular function in rats. Tohoku J. exp. Med. 120, 251-257.

LohiYA, N.K., Dixit, V.P. \& ARYA, M. (1976) Longterm effects of vasectomy on the pituitary-gonadal system of rat and mouse. Endokrinologie 67, 152-159.

MCGLynN, J.M. \& ERPino, M.J. (1974) Effects of vasectomy on the reproductive system and sexual behaviour of rats. J. Reprod. Fert. 40, 241-247.

Mock, E.J., Kamel, F., Wright, W.W. \& Frankel, A.I. (1975) Plasma testosterone levels in vasectomized rats. J. Reprod. Fert. 44, 575-578.

Neaves, W.B. (1973) Permeability of Sertoli cell tight junctions to lanthanum after ligation of ductus deferens and ductuli efferentes. J. Cell Biol. 59, 559572.

Neaves, W.B. (1974) The rat testis after vasectomy. $J$. Reprod. Fert. 40, 39-44.

Neaves, W.B. (1975a) Biological aspects of vasectomy. In Handbook of Physiology, Male Reproductive System, Section 7, Volume 5, pp. 383-404. Eds D. W. Hamilton \& R. O. Greep. American Physiological Society, Washington, D.C.

NeAves, W.B. (1975b) The androgen status of vasectomized rats. Endocrinology 96, 529-534.

ReINKE, L.A. \& SToHS, S.J. (1977) Lack of effect of vasectomy on hepatic mixed function monooxygenase enzymes in the rat. Contraception 15, 535542.

Sackler, A.M., Weltman, A.S., Pandhi, V. \& Schwartz, R. (1973) Gonadal effects of vasectomy and vasoligation. Science, N.Y. 179, 293-295.

SAdi, A., Chiorboli, E. \& SAAd, F. (1967) Vasectomia em ratos. Hospital, Rio de J. 72, 267-272. 
Thakur, A.N., Sheth, A.R. \& RAo, S.S. (1972) Biochemical studies on rat testes and sex accessory organs after vasoligation operation. Fert. Steril. 23, 834-837.

VOGLMAYR, J.K. (1975) Suppression of sperm granulomas in vasectomized rats by local heating of the testes. Biol. Reprod. 13, 453-460.
Vorsin, G.A. \& Toullet, F. (1969) Relation between hypersensitivity responses to autoantigens and tissue damage in the male reproductive tract. In Immunology and Reproduction, pp. 93-105. Ed. R. G. Edwards. International Planned Parenthood Federation, London.

Recelved 5 April 1978 